\title{
Review Article \\ Role of Melatonin in Traumatic Brain Injury and Spinal Cord Injury
}

\author{
Mehar Naseem and Suhel Parvez \\ Department of Medical Elementology and Toxicology, Jamia Hamdard, New Delhi 110062, India \\ Correspondence should be addressed to Suhel Parvez; sparvez@jamiahamdard.ac.in
}

Received 31 July 2014; Revised 11 November 2014; Accepted 14 November 2014; Published 21 December 2014

Academic Editor: Swapan Ray

Copyright (C) 2014 M. Naseem and S. Parvez. This is an open access article distributed under the Creative Commons Attribution License, which permits unrestricted use, distribution, and reproduction in any medium, provided the original work is properly cited.

Brain and spinal cord are implicated in incidences of two of the most severe injuries of central nervous system (CNS). Traumatic brain injury (TBI) is a devastating neurological deficit involving primary and secondary injury cascades. The primary and secondary mechanisms include complex consequences of activation of proinflammatory cytokines, cerebral edema, upregulation of NF- $\kappa \beta$, disruption of blood-brain barrier (BBB), and oxidative stress. Spinal cord injury (SCI) includes primary and secondary injury cascades. Primary injury leads to secondary injury in which generation of free radicals and oxidative or nitrative damage play an important pathophysiological role. The indoleamine melatonin is a hormone secreted or synthesized by pineal gland in the brain which helps to regulate sleep and wake cycle. Melatonin has been shown to be a versatile hormone having antioxidative, antiapoptotic, neuroprotective, and anti-inflammatory properties. It has a special characteristic of crossing BBB. Melatonin has neuroprotective role in the injured part of the CNS after TBI and SCI. A number of studies have successfully shown its therapeutic value as a neuroprotective agent in the treatment of neurodegenerative diseases. Here in this review we have compiled the literature supporting consequences of CNS injuries, TBI and SCI, and the protective role of melatonin in it.

\section{Introduction}

Central nervous system (CNS) is one of the complex systems in the body which consists of brain and spinal cord. Any disease or traumatic assault may lead to the degeneration of CNS including loss of homeostasis [1]. CNS injuries constitute a major cause of morbidity and mortality include the life threatening injuries such as traumatic brain injury (TBI) and spinal cord injury (SCI) [2-4]. TBI and SCI are caused by both primary and secondary injuries influencing the cascades of cellular and molecular events which will cause further damage in the system and loss of body functions. The consequences of the secondary injury include mitochondrial dysfunction, neurotransmitter accumulation, bloodbrain barrier (BBB) and blood spinal cord barrier disruption, apoptosis, excitotoxic damage, initiation of inflammatory, and immune processes which is followed by initial primary mechanical trauma $[5,6]$. Secondary injury involves the production of highly reactive species, reactive oxygen species
(ROS), reactive nitrogen species (RNS), or free radicals which will cause damage to protein structure, DNA, and cell membrane and leads to oxidative stress which plays a major role in the pathophysiology of CNS injury. The progression of the damage starts from the primary impact on brain or spinal cord and will continue for hours, days, and weeks after the initial mechanical insult which will result in tissue damage. This review in which two models of CNS injury will be covered will explore the role of reactive oxygen species (ROS) and current research on therapeutic role of melatonin used in the treatment of TBI and SCI.

\section{Oxidative Stress}

Oxidative stress is a phenomenon which occurs when there is an imbalance between prooxidants and antioxidants in the living system, which plays a major role in the pathophysiology of many disorders or injury. The cells of CNS have very low capacity to attenuate the effects of oxidative stress, so CNS is 
highly sensitive to oxidative stress and thus oxidative damage as the oxidative stress is associated with the pathogenesis of CNS injury such as stroke, TBI, and SCI.

There is a balance between the oxidants and antioxidants activities and when there is any disturbance caused by any environmental or genetic factor, excessive generation of free radicals or ROS occurs which overwhelms the endogenous antioxidant systems. Free radicals are highly reactive molecules having one or more unpaired electrons in their outermost orbits which result in their instability and make them more reactive as compared to their corresponding nonradicals. They participate in a number of reactions and form very reactive metabolites which includes hydroxyl radical ( $\left.\mathrm{HO}^{*}\right)$, hydrogen peroxide $\left(\mathrm{H}_{2} \mathrm{O}_{2}\right)$, singlet oxygen, and peroxynitrite. Superoxide anion radicals $\left(\mathrm{O}_{2}{ }^{-}\right)$which are derived from oxygen are the most commonly occurring and one of the strongest ROS among the cellular free radicals generated in living systems $[7,8]$. The superoxide radical which is considered as the "primary" ROS is capable of forming secondary ROS by reacting with other molecules. Superoxide dismutase (SOD) is a superoxide scavenging enzyme which plays the central role in amelioration of the effects of superoxide anion radicals by dismutation reaction in which it converts $\mathrm{O}_{2}{ }^{--}$into nonradical species, singlet oxygen, and hydrogen peroxide $\left(\mathrm{H}_{2} \mathrm{O}_{2}\right) \cdot \mathrm{H}_{2} \mathrm{O}_{2}$ forms highly reactive hydroxyl free radical $\left(\mathrm{OH}^{\circ}\right)$ via Fenton reaction which causes damage to lipid, proteins, and DNA, which is converted into $\mathrm{H}_{2} \mathrm{O}$ and oxygen by an antioxidant enzyme catalase $[9,10]$ (Figure 3 ). Reactive by-products of oxygen, such as superoxide anion radical $\left(\mathrm{O}_{2}^{-}\right), \mathrm{H}_{2} \mathrm{O}_{2}$, and the highly reactive hydroxyl radicals $\left({ }^{\circ} \mathrm{OH}\right)$, are formed continuously as a by-product of oxidative metabolism, catalysed by several membrane-associated respiratory chain enzymes and considered as the major source of oxidative injury in all aerobic organisms [11, 12].

ROS plays an important role as secondary messengers in many intracellular signalling pathways and also as mediators of oxidative damage and inflammation [13]. CNS has high levels of oxygen demand and unsaturated lipid content with which free radicals can easily react. Lipids are susceptible to oxidative stress and one of the products of oxidative damage to lipids is 4-hydroxy-2-nonenal (4-HNE) and acrolein and free radicals can attack directly polyunsaturated fatty acids in membranes and initiate lipid peroxidation (LPO). These features may make the CNS a target tissue for the onset and pathogenesis of a number of CNS disorders via oxygen radical production and LPO $[14,15]$. It has been well documented that in the CNS the transcription factor nuclear factor erythroid-2-related factor 2 (Nrf2) which is the principal regulator of phase- 2 cellular antioxidant response plays the central role in astrocyte-mediated protection of neurons from ROS [16].

\section{Traumatic Brain Injury}

TBI is devastating and a leading cause of injury related mortality and morbidity and may result in permanent functional impairment due to both primary which is caused by the initial mechanical injury and secondary injury mechanisms [1]. Primary injury is the initial traumatic brain insult, the consequences of which are immediate and irreversible disruption of neuronal cell bodies, contusion, vascular injury, and axon shearing. The primary injury also results in tissue deformation and compression, leading to seizures, respiratory depression, apnoea, ischemia, hypoxia, parenchymal inflammation, LPO, and nitric oxide production resulting in cellular injury [4]. The secondary injury which is a delayed nonmechanical insult to brain is caused by a complex cascade of metabolic, physiologic, and biochemical factors initiated by the primary insult, continuing for hours to days after injury that results in progressive tissue damage [5].

$\mathrm{Na}^{+}, \mathrm{K}^{+}$-ATPase is a membrane transport protein in mammalian cell membrane which plays an important role in maintaining ionic homeostasis. It is documented that any deregulation in the activity of the $\mathrm{Na}^{+}, \mathrm{K}^{+}$-ATPase pump might be a common feature in CNS pathologies related to ischemic conditions and TBI, since the pump is highly sensitive to reactive species and LPO and its decreased activity will increase the intracellular concentration of $\mathrm{Ca}^{2+}$, thus playing a synergistic role in excitotoxicity. The ischemic condition of the brain will lead to excitotoxicity which is induced by the release of excitatory amino acid neurotransmitters, particularly glutamate from neurons injured by ischemia, following which the subsequent activation of glutamate receptors resulted in a consecutive influx of $\mathrm{Ca}^{2+}, \mathrm{Na}^{+}$, and $\mathrm{K}^{+}$into neuronal cells through these receptors. Devastating effects of increased intracellular $\mathrm{Ca}^{2+}$ concentrations lead to the production of free radicals such as super oxide $\left(\mathrm{O}_{2}{ }^{-}\right)$and hydroxyl radical $\left({ }^{\circ} \mathrm{OH}\right)$ and synthesis of $\mathrm{NO}$ peroxidation of fatty acids, which can induce xanthine pathway and ultimately to degeneration in the cellular system and cell death by various mechanisms such as overactivation of phospholipases, calpains, protein kinases, and endonucleases [17, 18].

Brain has low level of antioxidant system and high oxidative utilization (20\% of the total oxygen inspired) as well as high level of polyunsaturated fatty acids (PUFA), transition metals such as iron, which is involved in the generation of the hydroxyl radical as compared to other organs which make it more susceptible to oxidative stress [19]. PUFA is very sensitive to free radicals which directly react with it and initiate LPO; during this process more radicals are formed which will disintegrate PUFA into a number of reactive products which will cause cellular damage. The deleterious effect of secondary injury to the brain revealed a number of experimental studies and oxidative stress which generates ROS one of the main cause of pathophysiologic processes after brain trauma, including mitochondrial dysfunction leading to energy failure, production of a large number of toxic and proinflammatory molecules, increase in intracranial pressure, and a subsequent decrease in cerebral perfusion leading to ischemia, astrocyte dysfunction, ATP depletion, proteolysis, and vasogenic edema [20]. Cerebral edema in TBI leads to exacerbating the severity of brain trauma by increasing intercranial pressure (ICP). Increased ICP is an important factor determining the outcomes of TBI patients and therefore it is measured. In an experimental study it was concluded that there was a significant rise in ICP in 4 and $24 \mathrm{~h}$ after brain injury in TBI compared to sham [21]. There are 
a number of studies which have been underexplored research area to cure secondary injury after TBI.

\section{Spinal Cord Injury}

SCI is a devastating event which initiates a series of complex cellular and molecular cascade events which leads to physical and social impact on individuals and society. The series of events lead to initial tissue damage in CNS. The pathophysiology of SCI is thought to include two stages: primary injury and secondary injury which is mediated by multiple injury processes including inflammation, autoimmune response, vascular events, apoptosis, free radical-induced cell death, and glutamate excitotoxicity [22]. The primary damage is restricted to the area of the mechanical insult and is characterized by ischemia. Neuroinflammation plays an important role in the pathogenesis of neuropathic pain. A major contributor to neuropathic pain in spinal cord injury is microglial activation and release of proinflammatory cytokines IL- $1 \beta$ and TNF- $\alpha$ that will enhance pain mechanism. In spite of many experimental studies, done so far or still in the process of investigation, there is no effective therapeutics which can eliminate the devastating effects of secondary damage after SCI. The severity of SCI depends on the extent of secondary damage mediated by multiple series of cellular, molecular, and biochemical reactions. The cascade of reactions includes calcium ion influx, oxygen free radical induced LPO, inflammatory reaction, autoimmune response, myelin degradation, and vascular changes (including ischemia, vasospasms, haemorrhages, and thrombosis). It also includes activation of a variety of proteases including caspases, phospholipases, endonucleases, metalloproteinases, and apoptosis which leads to the expansion of damage [23].

Inflammation acts as a key player in the pathogenesis of SCI leading to glial scar formation, neuronal loss and demyelination, and upregulation of proinflammatory cytokine TNF- $\alpha$ immediately after SCI, can enhance vascular permeability, and may cause damage to multiple organ system and finally in the neurological dysfunction or the most devastating result may come in the form of permanent loss of motor, sensory, and autonomic function due to inability of the adult mammalian nervous system to regenerate [32-34]. ROS including $\mathrm{O}_{2}^{-}, \mathrm{H}_{2} \mathrm{O}_{2}, \mathrm{OH}^{*}$, and peroxynitrite are believed to attack unsaturated fats, lipids, proteins, DNA and also play an important role to exacerbate the ill effects of the secondary injury. Like brain, spinal cord is also susceptible to oxidative damage because of having rich in PUFA acids [35]. Oxidative stress is one of the well-defined consequences which plays a significant role in the pathophysiology of SCI and is considered as a hallmark of secondary injury. After the mechanical insult caused to spinal cord generation of free radical superoxide $\left(\mathrm{O}_{2}{ }^{--}\right)$occurs within the first minutes and hours of injury [36].

\section{Proposed Neuroprotective Therapies for TBI and SCI in Animal Model}

Endogenously occurring hormones or other compounds such as progesterone [21,37], estrogen [1], and lipoic acid [38] have been studied for their multifaceted role in neuroprotection. Among the endogenous compounds melatonin represents one of the best promising candidates to be studied for its role in neuroprotection (Table 1).

\section{Biology of Melatonin}

Melatonin (N-acetyl-5-methoxytryptamine), an amphiphilic molecule, was isolated by Lerner and his coworkers in 1956 in the extract of bovine pineal tissue with skin lightening properties $[39,40]$. Melatonin is a methoxyindole derivative produced by extra pineal tissues and organs such as retina, Harderian gland, gut, bone marrow, platelets, astrocytes, glial cells, lymphocytes, pancreas, kidneys, and skin but predominantly by the pineal gland. It is synthesized by pinealocytes which is the main source of melatonin in blood and CNS that peaks during the night in mammals and considered as a powerful antioxidant [41]. Melatonin occurrence has been well documented in animals but its occurrence in plants has also been mentioned [42].

The rate of endogenous melatonin synthesis depends on the action of its precursors, the amino acid as well as a neurotransmitter serotonin, arylalkylamine $\mathrm{N}$-acetyltransferase, (AANAT) and tryptophan hydroxylase (TPH) in a circadian and seasonal manner [40] (Figure 1). There are a number of studies where melatonin has been shown to regulate various physiological functions in the body such as immune enhancing, anti-inflammatory properties [43], radicals scavenger [44], traumatic CNS injury [4], modulation of human mood and behaviour [45], anticancer activity [46, 47], in oral cavity [48], against angiogenesis in breast tumors [49], sleep regulation [50].

Melatonin activity is mediated by the specific receptors in cellular membranes by two high affinity melatonin receptors, MT1 and MT2, which belong to the seven-transmembrane Gprotein-coupled receptor (GPCR) superfamily and through nuclear receptors RZR/ROR. These melatonin receptors, MT1 and MT2, are primarily found in the endogenous circadian master clock suprachiasmatic nuclei (SCN) in the hypothalamus of the mammalian cells, being localized primarily to neuronal elements and in many other organs as well, coordinate the synthesis of melatonin in the pineal gland, and also participate in several neuroendocrine and physiological processes. Melatonin receptors are widely distributed in CNS as well as in the peripheral organs which acts as a lipophilic and hydrophilic molecule and able to pass the morphophysiological barriers such as the BBB. Its neuroprotective nature has also been described through the activation of these receptors but the actual mechanism is unknown.

Metabolisation of melatonin occurs by cytP-450 enzyme which metabolises it into 6-hydroxymelatonin which is followed by conjugation reaction resulting into the formation of 6-sulfatoxymelatonin [43]. In a recent experimental study it was shown that there were an increased number of MT1 receptors patients as compared to MT2 receptors where no alteration has been shown in the SCN of depressed person [51]. It also has an affinity for a third melatonin receptor, considered to represent a membrane-bound receptor (MT3), 


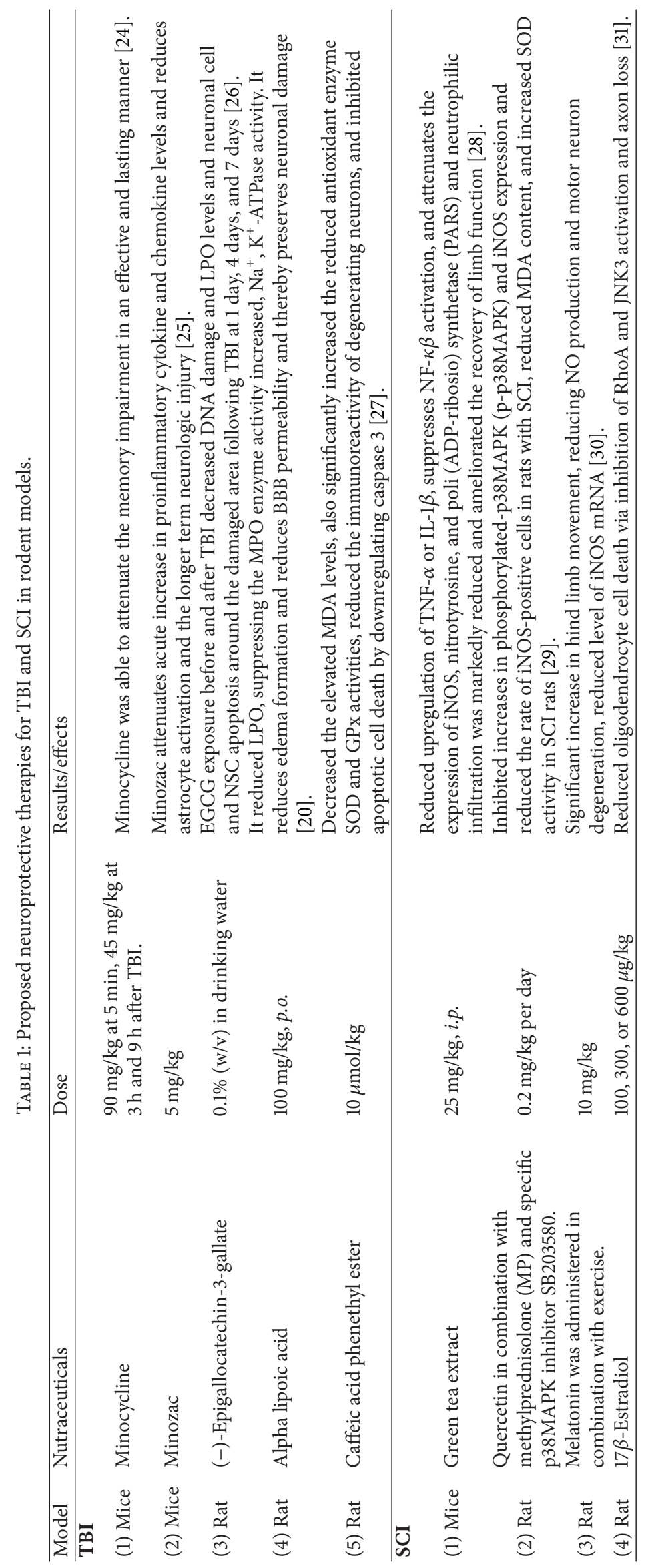




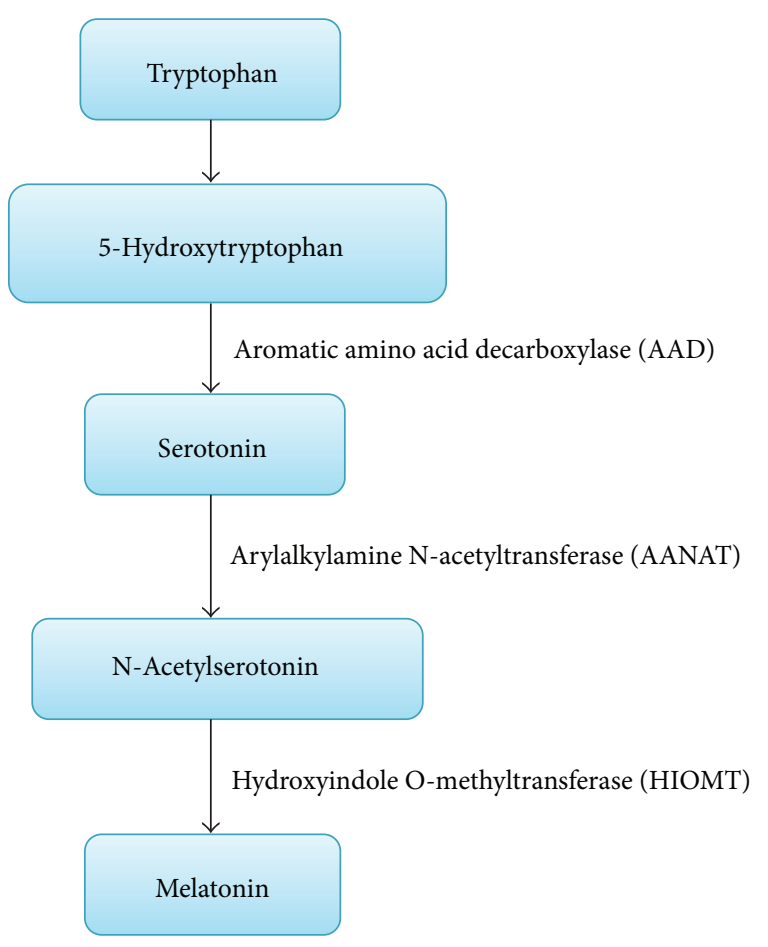

Figure 1: Biochemical synthesis of melatonin. Tryptophan acts as a precursor for melatonin synthesis. AAD is responsible for the conversion of 5-hydroxytryptophan into serotonin. Melatonin is formed from serotonin through a phase of reaction with the help of two enzymes, AANAT and HIOMT. Acetylation of serotonin occurs with the action of AANAT which forms $\mathrm{N}$-acetylserotonin and subsequently HIOMT converts $\mathrm{N}$-acetylserotonin into melatonin.

identical to the cytosolic enzyme, quinone reductase $2(\mathrm{QR} 2)$ [52]. Melatonin may be used for the treatment of sleep disorders, such as insomnia as it is having hypnotic and chronobiotic properties [53]. ROS generation is a continuous phenomenon in cells and the cells have their own antioxidant system to combat this oxidative stress which is a consequence of free radicals and one of the pathophysiological causes of neurological disorders [54]. It is well documented in previous literatures that the melatonin regulates the enzymes involved in redox cycle and is a potent free radical scavenger, as its administration maintains the ratio of GSH/GSSG and LPO during aging seen in the brain mitochondria of male as well as female mice [19].

It has also been demonstrated that melatonin regulates both the electron transport chain and oxidative phosphorylation by maintaining ATP level in normal cells and also during aging. It is lipophilic in nature so it gets accumulated in the mitochondria at higher concentration and interacts with mitochondrial membrane so as to protect the brain mitochondrial membranes and mtDNA as well as electron transport chain from the damage caused by ROS/RNS by radical avoidance accomplished without the intervention of a receptor [55]. Melatonin is a broad-spectrum antioxidant and versatile as compared to its naturally occurring molecular analogs.

\section{Melatonin: As a Neuroprotectant}

The research has been in process for more than 10-12 years which has proved melatonin's beneficial effects in experimental models of neurodegenerative disorders and CNS injuries. The neuroprotective effects of melatonin appear to be mediated by the antioxidant capacity of this pineal hormone. The neuroprotective effects of melatonin may also be due to the specific interactions of its indole moiety with its receptors. Activated melatonin receptors of the brain take part in the regulation of the levels of neurotrophic factors such as brainderived neurotrophic factor (BDNF), which has an important role in the maintenance of neuronal cells and is widely distributed in the central nervous system [56]. Increasing melatonin bioavailability decreased the severity of hemi-Parkinson conditions caused by 6-OHDA.

It has been reviewed that melatonin plays a great role in antiapoptotic activities via the inhibition of intrinsic apoptotic pathways and the activation of several signal pathways in stroke, Alzheimer's disease, Parkinson's disease (PD), Huntington's disease, and amyotrophic lateral sclerosis [57]. In an experimental study it was concluded that post-treatment process with melatonin individually or in combination with uridine can reduce posttraumatic edema in various brain regions in traumatic brain injury model [56]. In an experimental study it was evaluated that the treatment with melatonin (5 and $10 \mathrm{mg} / \mathrm{kg}$, ip) improved the survival rate in a stroke model of mice and restored the integrity of BBB by mitigating the effect of ROS production and gp91phox cell infiltration [58]. Melatonin has been evaluated to be effective in TBI where it decreases brain edema, BBB permeability, and intercranial pressure and significantly increased superoxide dismutase (SOD) and glutathione peroxidase (GPx) activities whereas decreased malondialdehyde levels [59].

Melatonin has been shown to be protective in Parkinson's disease (PD) as it is tested in an experimental study that in combination with silymarin, it provides neuroprotection against manganese ethylenebisdithiocarbamate and $1,1^{\prime}$-dimethyl-4,4' -bipyridinium (paraquat) induced PD [60]. Melatonin plays a significant neuroprotective role in mitigating the cognitive impairment induced by sleep deprivation (SD) and also restores the levels of oxidative stress markers including NO and MDA as well as SOD activity [23].

\section{Melatonin: As an Antioxidant}

Melatonin as well as several of its metabolites is proved to be an effective antioxidant as its antioxidative property is also synergised by its metabolites formed from the free radical scavenging and also functions as an efficient radical scavenger [42]. Melatonin undergoes oxidation reaction resulting in the formation of cyclic 3-hydroxymelatonin (C3-OHM) which functions as a radical scavenger and scavenges two - $\mathrm{OH}$ resulting into the formation of N1-acetyl-N2-formyl5-methoxykynuramine (AFMK) [61]. AFMK is also formed directly from the melatonin when melatonin reacts with $\mathrm{H}_{2} \mathrm{O}_{2}$. AMK (N1-acetyl-5-methoxykynuramine) may even be a potent free radical scavenger of nitric oxide $(\mathrm{NO})$ compared to its precursor AFMK which is formed from AFMK via 


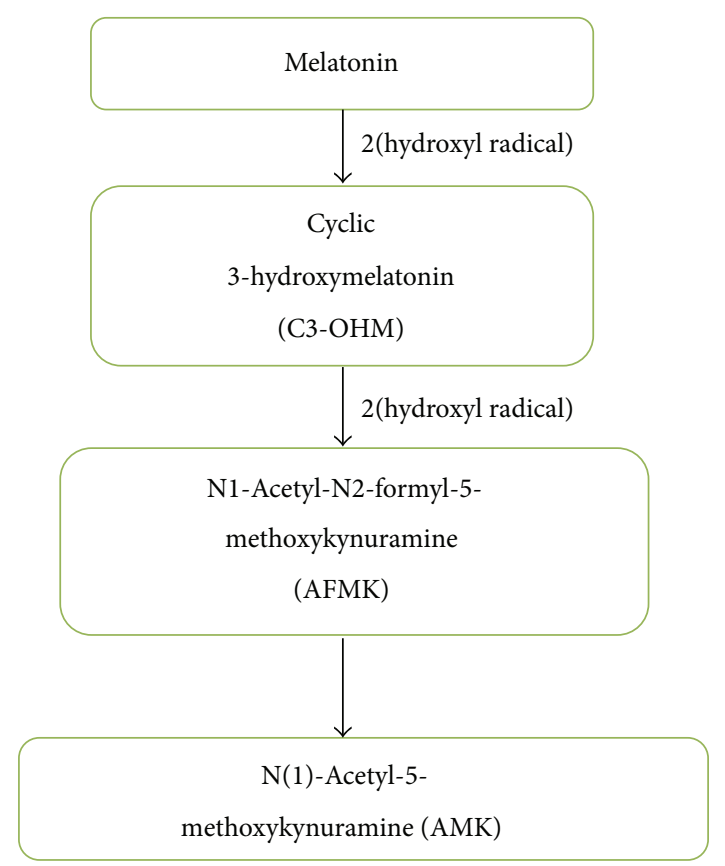

FIGURE 2: Mechanism for the formation of metabolites by oxidative pyrrole ring cleavage of melatonin forming a primary metabolite AFMK. The secondary metabolite AMK has potent radical scavenging properties as compared to AFMK, formed during the oxidation of melatonin by hydroxyl radicals $\left({ }^{\circ} \mathrm{OH}\right)$ as a result of pyrrole ring cleavage.

pyrrole ring cleavage [43] (Figure 2). In a recent experimental research it was concluded that oral administration of melatonin $(10 \mathrm{mg} / \mathrm{kg})$ induced a significant decrease in brain malonaldehyde (MDA) level and raised brain glutathione peroxidase activity against diazinon induced neurotoxicity [62]. It is also documented that melatonin $(5$ and $20 \mathrm{mg} / \mathrm{kg}$, i.p.) was effective against the increase in reactive species and protein carbonyl levels as well as the inhibition of superoxide dismutase activity [63]. Exposure of animals to melatonin decreased LPO, restored GSH content, and mitigated the activities of CAT, SOD, and GPx in the brain from cholestatic animals. The neuroprotective effect of melatonin was shown to be more evident in the cortical and cerebral areas where it reduced the MDA content [64].

It is well documented in a number of studies that CNS is susceptible to oxidative stress or nitrosative stress caused by ROS/RNS which may cause neuronal damage if the severe effects of ROS are not suppressed or if they are not eliminated. Melatonin is an endogenously occurring hormone and is also considered as a potent antioxidant which protects the various organs of the body via its antioxidative mechanism. Melatonin is capable of scavenging a variety of ROS and RNS including hydroxyl radical $\left(\mathrm{HO}^{\circ}\right)$, superoxide anion radical $\left(\mathrm{O}_{2}{ }^{--}\right)$, hydrogen peroxide $\left(\mathrm{H}_{2} \mathrm{O}_{2}\right)$, nitric oxide $\left(\mathrm{NO}^{\circ}\right)$, and peroxynitrite anion $\left(\mathrm{ONOO}^{-}\right)$and at the same time it also activates several antioxidant enzymes, including glutathione peroxidase, superoxide dismutase, and catalase. From this it can be concluded that melatonin has been used as an antioxidant from many years and several of its metabolites are also able to protect cells from oxidative damage caused by reactive species and it amplifies the antioxidant capacity of melatonin.

\section{Neuroprotective Mechanisms of Melatonin in TBI}

9.1. Reduced Inflammation. Inflammation after the mechanical insult exacerbates the devastating effects of CNS injury. CNS injury such as SCI produces a marked neuroinflammatory response characterized by influx of monocytes such as macrophages and neutrophils, activation of microglial cells and astrocytes which contribute to the secondary pathological and inflammatory response, upregulation of proinflammatory cytokines such as IL- $\alpha$, IL- $1 \beta$, IL- 6 , TNF- $\alpha$, interferon-Y, and intracellular adhesion molecules (ICAM1), and also contributed to neuroinflammation which have contributed to facilitate CNS inflammatory responses by inducing expression of ROS such as superoxide radical and nitric oxide (NO) and chemokines, which inhibit the process of neurogeneration and also exacerbate cerebral damage, inflammation of which has a great role in the pathogenesis of secondary injury in TBI $[65,66]$. It has been reported that melatonin has a potential role in deactivating the release of proinflammatory cytokines in TBI [43].

9.2. Reduced Edema. Cerebral edema is the critical factor involved in the pathogenesis of secondary injury in TBI. Different reasons have been suggested for the occurrence of edema in TBI such as swelling of damaged cells and injury to blood vessels that forces fluid to enter the various regions of brain and blood-brain barrier breakdown and increase of endothelium permeability and vascular permeability. Cerebral edema can be classified into two main categories, namely, cytotoxic edema (closed barrier) or vasogenic edema (open barrier). Vasogenic brain edema is characterized by the structural and functional disruption of the blood-brain barrier and involves accumulation of proteins due to increased permeability of endothelial cells to albumin, dextran, and so forth, whereas cytotoxic edema is the result of cellular uptake and cell swelling without interfering the integrity of bloodbrain barrier. Cerebral edema when left untreated results in an increase in intracranial pressure that may lead to limiting cerebral perfusion, oxygenation of the tissue, distortion, herniation, and even death [67]. Previous studies have shown that administration of melatonin after TBI in albino N-Mary rats model decreases brain edema, BBB permeability, and ICP at $72 \mathrm{~h}$ after TBI at low as well as high dose [59]. In an another study administration of melatonin $(200 \mathrm{mg} / \mathrm{kg})$, both individually and in combination with uridine, reduced posttraumatic edema in various brain regions of male SpragueDawley rat model of TBI [56].

9.3. Regulation of NF- $\kappa \beta$. It has been well documented in a previous study that transcription factor (NF- $\kappa \beta)$ has diverse function in regulating synaptic transmission and plasticity, spatial memory function, and development and increased 


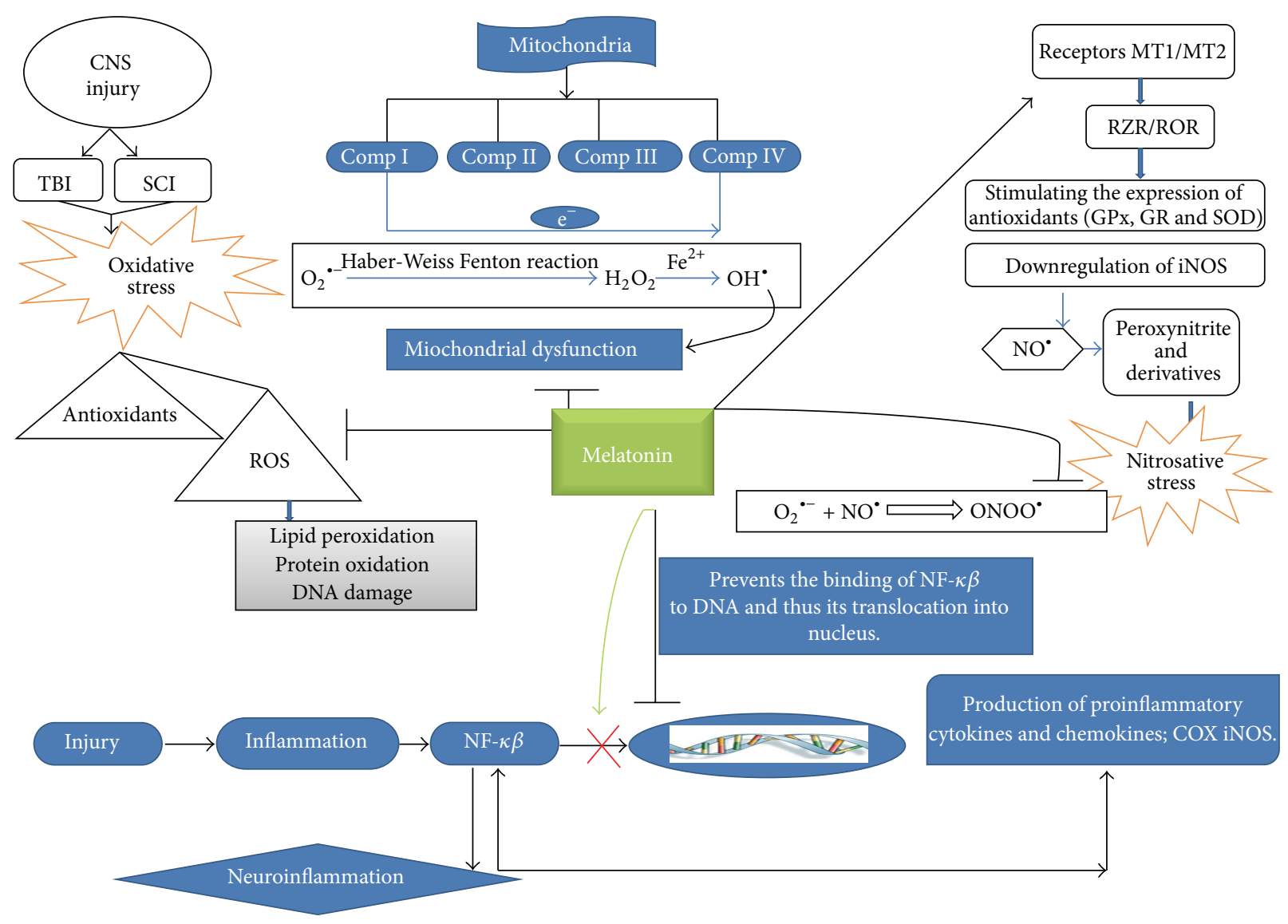

FIGURE 3: Role of melatonin in several stress conditions. CNS injury includes TBI and SCI which leads to oxidative stress which promotes ROS at a very high level compared to that of antioxidants and plays an important role in the pathogenesis of disease. ROS reacts with PUFA of lipid membranes which results in lipid peroxidation. ROS can also damage DNA and protein which leads to protein oxidation and DNA damage. Melatonin acts as a radical scavenger as it reduces the level of ROS. Fenton reaction leads to the production of hydroxyl radical OH associated with mitochondrial complexes and melatonin has metal binding capacity which may form chelating compound and reduce $\mathrm{OH}$ generation. Melatonin is a natural ligand for a nuclear retinoid related orphan nuclear hormone receptor superfamily RZR/ROR. Melatonin involves the regulation of expression antioxidant enzymes like GPx, GR, and SOD by involving MT1/MT2 and ROR receptors. Melatonin acts as an antinitrosative agent by reducing ONOO. CNS injury triggers cerebral inflammation which involves NF- $\kappa \beta$ which is a key player in secondary injury. Here melatonin acts as an antineuroinflammatory agent and inhibits the activation of NF- $\kappa \beta$ and its binding to DNA.

activation of which has been seen after different pathological conditions including traumatic brain injury, ischemia [68]. The mRNA expressions of NF- $\kappa \beta$ were shown to be upregulated remarkably following TBI [35]. Efficacy of melatonin is investigated in alteration of the molecular changes that occur as a result of closed head injury (CHI). Melatonin totally blocks the late-phase activation of NF- $\kappa \beta$ and decreases that of AP-1 to half the basal level. An effective dose of melatonin $5 \mathrm{mg} / \mathrm{kg}$ has shown the significant effect by mitigating damage [69].

9.4. Regulation of $B B B$ Integrity. TBI can result in brain and $\mathrm{BBB}$ disruption resulting into increased $\mathrm{BBB}$ permeability. Disruption of the BBB may lead to astrocytic dysfunction, inflammation-related mechanisms, and permeability to endogenous proteins which may cause brain dysfunction [70,
71]. In a clinical study it was quantified that there was a lasting focal increase in BBB permeability in up to $70 \%$ of TBI patients [72]. In a recent study it was documented that melatonin administration in both low and high doses can significantly decrease blood-brain barrier permeability at $72 \mathrm{~h}$ after TBI [59].

9.5. Reduced Oxidative Damage. Oxidative stress plays an important role in the pathogenesis of secondary injury following TBI. It was evaluated in a study that the brain GSH content decreased significantly and TBARS level which is the by-product of LPO increased significantly, resulting into enhanced LPO following TBI [20]. LPO is the process in which free radicals steal electrons from the lipids and cause degradation of lipids and ultimately cell membrane. Melatonin has been shown to be a good neuroprotectant in various 
studies by suppressing oxidative stress markers and by upregulating endogenous antioxidants maybe due to its lipid soluble characteristic due to which it easily crosses morphophysiological barriers which make melatonin an ideal antioxidant and its antioxidative action is independent of receptors [52]. Recently it has been found that daily administration of melatonin after TBI increases SOD and GPX activity and decreases the MDA level significantly within $72 \mathrm{~h}$ and thus protected cerebral tissue against oxidative stress [59].

\section{Neuroprotective Role of Melatonin in SCI}

10.1. Reduced Inflammation. In an experimental literature it was demonstrated that proinflammatory cytokines such as interleukin 1 (IL- $1 \alpha)$ and IL-1 $\beta$ are activated within the few hours in SCI [73]. It has been demonstrated that IL-6 plays a great role in the pathogenesis of proinflammatory damage after SCI and TNF- $\alpha$ which is having a significant role in immune and vascular responses and is released early after the inflammation plays a pivotal role in the process of inflammation by increasing the number of inflammatory and immune cells to the injured site [33]. Activation of NF- $\kappa \beta$ signalling pathway has been shown to be important for the induction of inflammation and a pathophysiologic cause of spinal cord inflammatory response after injury and it also takes part in the generation of ROS and prostaglandins (COX and iNOS) which act to synergise the effects of inflammation [33]. In an experimental literature it was concluded that the levels of the p65 subunit protein in the nuclear fractions of the spinal cord tissue were significantly increased at $24 \mathrm{~h}$ after SCI [28]. In response to the inflammation proinflammatory cytokines, the invasion of neutrophils and CNS macrophages is shown to be greater in spinal cord [74]. Melatonin which is an endogenous hormone produced by tryptophan shows its potency of neuroprotection, suppresses the expression of NF$\kappa \beta$ regulated adhesion molecules, and reduces the production of proinflammatory cytokines [75]. If we consider the findings during the past few years, then there are strong evidences of this hormone that it could be a key player in preventing the severity of secondary damage which could lead to the neuronal death, by improving the recovery function in injured neuronal cells [76]. It has been well documented that melatonin is also protective against the devastating effects of inflammation by reduction of the production of several proinflammatory cytokines thus preventing neurons which results from the various neurological disorders [77]. In another study it was concluded that melatonin treatment was effective in reducing the activation of inflammation and tissue injury in an animal model of spinal cord injury [78].

10.2. Regulation of iNOS. Nitric oxide (NO) which is a neurotransmitter, as well as a free radical, is able to form peroxynitrite $\left(\mathrm{ONOO}^{-}\right)$by reacting with superoxide forming a more potent and devastating oxidant [79]. NOS exists in three genetically different isoforms: neuronal NOS (nNOS, NOSI), located within central and peripheral neurons and some other types of cell, inducible NOS (iNOS, NOS II) which is $\mathrm{Ca}^{2+}$-calmodulin independent enzyme associated mainly with macrophages and microglial cells, and endothelial NOS (eNOS, NOS III), expressed within vessel endothelia [30, 80, 81]. Nitric oxide is produced from L-arginine-NO pathway by the NO synthase involving NADPH and $\mathrm{O}_{2}$ and $\mathrm{NO}$ is involved in several cellular functions, such as neurotransmission, regulation of vascular tone, apoptosis, and immune system [82]. In an experimental study it was investigated that all SCI groups showed an upregulated iNOS mRNA expression in damaged regions of the spinal cord compared with animals with an intact spinal cord and highest expression of iNOS mRNA was detected at 3 days after injury and it was shown that administration of melatonin $10 \mathrm{mg} / \mathrm{kg}$ body weight significantly diminished iNOS expression and NO production [30].

10.3. Regulation of MAPK. Mitogen-activated protein kinases (MAPKs) which play important roles in cell signalling and gene expression consist of the extracellular signal-regulated protein kinase (ERK), c-Jun N-terminal kinase (JNK), and p38 pathways, in which p38 MAPK is regarded as a stressinduced kinase $[83,84]$. In a study a significant increase in phosphorylated-pERK1/2 levels was observed in mice model of SCI [85]. In an experimental study it was reported that $24 \mathrm{~h}$ postspinal cord trauma a dose of $50 \mathrm{mg} / \mathrm{kg}$ melatonin reduced activation of MAPKs p38, JNK, and ERK1/2 [86].

10.4. Reduced Oxidative Stress. Oxidative stress by free radical generation and LPO are the hallmarks of secondary injury caused by SCI. In recent years, much attention has been focused on oxidative stress cascade leading to secondary injury after SCI because inhibition of the deleterious effects of it is thought to be one of the main mechanisms of therapeutic interventions [87]. ROS and RNS are the free radicals which cause devastating effects in biological system [88]. Recently it has been shown that MDA content significantly increased at 1 day after injury and reached a peak value at 7 days in the SCI group and SOD activity was significantly reduced in the SCI group at 1 day. From 1 to 14 days, SOD activity was significantly reduced in the SCI group [29]. Melatonin and its metabolic derivatives have been documented to be an effective direct free radical scavenger and also stimulate the activities of several endogenous antioxidative enzymes [89]. In a SCI model of Wistar albino rats, MDA level was found to be increased in spinal cord in SCI group of animals while treatment with melatonin attenuated the elevated levels in MDA level in spinal cord tissue. SCI has also been shown to cause a significant decline in GSH level whereas treatment with melatonin $(10 \mathrm{mg} / \mathrm{kg})$ was able to restore the decreased level of GSH level in spinal cord tissue [90].

\section{Adverse Effects of Melatonin}

Melatonin is a hormone which is the main secretory product of pineal gland and has been shown to exhibit antioxidant properties by increasing intracellular antioxidants activity or acting as a direct radical scavenger. However recent evidences indicate that melatonin is also able to generate intracellular ROS [91, 92]. The deleterious effect of melatonin is not much 
explored even though it can cross cell membranes due to its amphilicity as it has been shown to decrease intracellular free thiols by melatonin [93]. It has been explored that the activity of intracellular activity GSH reduced due to melatonin treatment in U937 cells which is correlated to its ability to produce intracellular ROS after a certain time period [91]. ROS may be involved in inducing apoptosis as seen in various studies and thus act as a prooxidant as well as a proapoptotic factor for causing apoptosis [94, 95]. Various studies on antiapoptotic activity of melatonin are reported in which the administration of exogenous melatonin has been shown to be effective in preventing normal cells from apoptosis in in vitro $[96,97]$ as well as in vivo [98]. But research reports also indicate melatonin has been reported to have proapoptotic and cytotoxic features in several cancer cells including the human myeloid cell line HL-60 [99-101]. Its cytotoxicity in Caco-2 cells in certain concentration range has been well proved in a recent study [102]. In a study it was shown that melatonin in Jurkat cells was responsible for prooxidant activity [103].

\section{Protective Role of Melatonin in Human}

Melatonin has been shown to be effective in neuroprotection in various animal models [104-107]. However a number of scientific literatures have also investigated the neuroprotective role of melatonin in human. Melatonin which is the main secretory body of pineal gland is believed to be an important part in sleep/wake cycle regulation and also the sleep disorder in old age people [108]. The biological clock in the hypothalamic suprachiasmatic nucleus $(\mathrm{SCN})$ regulates melatonin secretion by the pineal gland as well as circadian rhythm regulation [109]. Endogenous melatonin as well as exogenous melatonin has been seen to be effective in combating oxidative stress in brain. It has long been well reported that the level of endogenous CSF melatonin increases in TBI patients to suppress the level of oxidants which has a direct link in the pathogenesis of brain injury [110]. In a double blind study melatonin seemed to be effective in treating Alzheimer type dementia (ATD) which is a progressive fatal neurodegenerative [109]. Delirium is a common neuropsychiatric condition which has shown to be decreased by exogenous supplementation of melatonin in elderly patients [108].

In conclusion, melatonin has been documented to be a potent neuroprotective agent in rodent models of traumatic brain injury and spinal cord injury. Melatonin, which is secreted by the pineal gland, is a powerful scavenger of reactive oxygen species. Additionally, melatonin is able to increase the activity and expression of antioxidant enzyme activity under both physiological conditions of elevated oxidative stress. Its inherent property of crossing the blood-brain barrier makes it more effective in mediating neuroprotection.

\section{Conflict of Interests}

The authors declare that there is no conflict of interests regarding the publication of this paper.

\section{Acknowledgments}

The Grant (no. F. 30-1/2013(SA-II)/RA-2012-14-GE-WES2400), received as Research Award (2012-14) from the University Grants Commission (UGC), New Delhi, Government of India to Dr. Suhel Parvez, is thankfully acknowledged. Mehar Naseem is grateful to UGC, for financial grant (Maulana Azad National Fellowship, sanction no. MANF-2013-14MUS-JHA-30114).

\section{References}

[1] S. Samantaray, N. P. Thakore, D. D. Matzelle, A. Varma, S. K. Ray, and N. L. Banik, "Neuroprotective drugs in traumatic CNS injury," The Open Drug Discovery Journal, vol. 2, no. 3, pp. 174$180,2010$.

[2] O. G. Bhalala, M. Srikanth, and J. A. Kessler, "The emerging roles of microRNAs in CNS injuries," Nature Reviews Neurology, vol. 9, no. 6, pp. 328-339, 2013.

[3] H. Kim, M. J. Cooke, and M. S. Shoichet, "Creating permissive microenvironments for stem cell transplantation into the central nervous system," Trends in Biotechnology, vol. 30, no. 1, pp. 55-63, 2012.

[4] S. Samantaray, A. Das, N. P. Thakore et al., "Therapeutic potential of melatonin in traumatic central nervous system injury," Journal of Pineal Research, vol. 47, no. 2, pp. 134-142, 2009.

[5] M. Bains and E. D. Hall, "Antioxidant therapies in traumatic brain and spinal cord injury," Biochimica et Biophysica Acta, vol. 1822, no. 5, pp. 675-684, 2012.

[6] A. R. khalatbary, T. Tiraihi, M. B. Boroujeni, H. Ahmadvand, M. Tavafi, and A. Tamjidipoor, "Effects of epigallocatechin gallate on tissue protection and functional recovery after contusive spinal cord injury in rats," Brain Research, vol. 1306, pp. 168-175, 2010.

[7] O. A. Aiyegoro and A. I. Okoh, "Preliminary phytochemical screening and in vitro antioxidant activities of the aqueous extract of Helichrysum longifolium DC," BMC Complementary and Alternative Medicine, vol. 10, article 21, 2010.

[8] K. Dohi, H. Ohtaki, T. Nakamachi et al., "Gp91 phox (NOX2) in classically activated microglia exacerbates traumatic brain injury," Journal of Neuroinflammation, vol. 7, article 41, 2010.

[9] Y. Han, S. DeMorrow, P. Invernizzi et al., "Melatonin exerts by an autocrine loop antiproliferative effects in cholangiocarcinoma: its synthesis is reduced favoring cholangiocarcinoma growth," American Journal of Physiology: Gastrointestinal and Liver Physiology, vol. 301, no. 4, pp. G623-G633, 2011.

[10] K. Jomova, D. Vondrakova, M. Lawson, and M. Valko, "Metals, oxidative stress and neurodegenerative disorders," Molecular and Cellular Biochemistry, vol. 345, no. 1-2, pp. 91-104, 2010.

[11] A. Clausen, S. Doctrow, and M. Baudry, "Prevention of cognitive deficits and brain oxidative stress with superoxide dismutase/catalase mimetics in aged mice," Neurobiology of Aging, vol. 31, no. 3, pp. 425-433, 2010.

[12] T. B. Kryston, A. B. Georgiev, P. Pissis, and A. G. Georgakilas, "Role of oxidative stress and DNA damage in human carcinogenesis," Mutation Research/Fundamental and Molecular Mechanisms of Mutagenesis, vol. 711, no. 1-2, pp. 193-201, 2011.

[13] S. Waldbaum and M. Patel, "Mitochondrial dysfunction and oxidative stress: a contributing link to acquired epilepsy?" Journal of Bioenergetics and Biomembranes, vol. 42, no. 6, pp. 449-455, 2010. 
[14] O. Ates, S. Cayli, E. Altinoz et al., "Neuroprotection by resveratrol against traumatic brain injury in rats," Molecular and Cellular Biochemistry, vol. 294, no. 1-2, pp. 137-144, 2007.

[15] M.-J. Tsai, J.-F. Liao, D.-Y. Lin et al., "Silymarin protects spinal cord and cortical cells against oxidative stress and lipopolysaccharide stimulation," Neurochemistry International, vol. 57, no. 8, pp. 867-875, 2010.

[16] R. H. Scannevin, S. Chollate, M.-Y. Jung et al., "Fumarates promote cytoprotection of central nervous system cells against oxidative stress via the nuclear factor (erythroid-derived 2)like 2 pathway," Journal of Pharmacology and Experimental Therapeutics, vol. 341, no. 1, pp. 274-284, 2012.

[17] T. Itoh, T. Satou, S. Nishida et al., "Edaravone protects against apoptotic neuronal cell death and improves cerebral function after traumatic brain injury in rats," Neurochemical Research, vol. 35, no. 2, pp. 348-355, 2010.

[18] T. Itoh, M. Imano, S. Nishida et al., "Exercise inhibits neuronal apoptosis and improves cerebral function following rat traumatic brain injury," Journal of Neural Transmission, vol. 118, no. 9, pp. 1263-1272, 2011.

[19] M. Carretero, G. Escames, L. C. López et al., "Long-term melatonin administration protects brain mitochondria from aging," Journal of Pineal Research, vol. 47, no. 2, pp. 192-200, 2009.

[20] H. Z. Toklu, T. Hakan, N. Biber, S. Solakoğlu, A. V. Öğünç, and G. Şener, "The protective effect of alpha lipoic acid against traumatic brain injury in rats," Free Radical Research, vol. 43, no. 7, pp. 658-667, 2009.

[21] F. Maghool, M. Khaksari, and A. Siahposht Khachki, "Differences in brain edema and intracranial pressure following traumatic brain injury across the estrous cycle: involvement of female sex steroid hormones," Brain Research, vol. 1497, pp. 61$72,2013$.

[22] A. R. Khalatbary and H. Ahmadvand, "Anti-inflammatory effect of the epigallocatechin gallate following spinal cord trauma in rat," Iranian Biomedical Journal, vol. 15, no. 1-2, pp. 31-37, 2011.

[23] L. Zhang, H.-Q. Zhang, X.-Y. Liang, H.-F. Zhang, T. Zhang, and F.-E. Liu, "Melatonin ameliorates cognitive impairment induced by sleep deprivation in rats: role of oxidative stress, BDNF and CaMKII," Behavioural Brain Research, vol. 256, pp. 72-81, 2013.

[24] E. Siopi, G. Llufriu-Dabén, F. Fanucchi, M. Plotkine, C. Marchand-Leroux, and M. Jafarian-Tehrani, "Evaluation of late cognitive impairment and anxiety states following traumatic brain injury in mice: the effect of minocycline," Neuroscience Letters, vol. 511, no. 2, pp. 110-115, 2012.

[25] E. Lloyd, K. Somera-Molina, L. J. van Eldik, D. M. Watterson, and M. S. Wainwright, "Suppression of acute proinflammatory cytokine and chemokine upregulation by post-injury administration of a novel small molecule improves long-term neurologic outcome in a mouse model of traumatic brain injury," Journal of Neuroinflammation, vol. 5, article 28, 2008.

[26] T. Itoh, M. Imano, S. Nishida et al., "Epigallocatechin-3gallate increases the number of neural stem cells around the damaged area after rat traumatic brain injury," Journal of Neural Transmission, vol. 119, no. 8, pp. 877-890, 2012.

[27] M. Kerman, M. Kanter, K. K. Coşkun, M. Erboga, and A. Gurel, "Neuroprotective effects of Caffeic acid phenethyl ester on experimental traumatic brain injury in rats," Journal of Molecular Histology, vol. 43, no. 1, pp. 49-57, 2012.

[28] I. Paterniti, T. Genovese, C. Crisafulli et al., “Treatment with green tea extract attenuates secondary inflammatory response in an experimental model of spinal cord trauma," NaunynSchmiedeberg's Archives of Pharmacology, vol. 380, no. 2, pp. 179-192, 2009.

[29] Y. Song, J. Liu, F. Zhang, J. Zhang, T. Shi, and Z. Zeng, "Antioxidant effect of quercetin against acute spinal cord injury in rats and its correlation with the p38MAPK/iNOS signaling pathway," Life Sciences, vol. 92, no. 24-26, pp. 1215-1221, 2013.

[30] K. Park, Y. Lee, S. Park et al., "Synergistic effect of melatonin on exercise-induced neuronal reconstruction and functional recovery in a spinal cord injury animal model," Journal of Pineal Research, vol. 48, no. 3, pp. 270-281, 2010.

[31] J. Y. Lee, S. Y. Choi, T. H. Oh, and T. Y. Yune, "17 $\beta$-estradiol inhibits apoptotic cell death of oligodendrocytes by inhibiting Rhoa-JNK3 activation after spinal cord injury," Endocrinology, vol. 153, no. 8, pp. 3815-3827, 2012.

[32] M. B. Leal-Filho, "Spinal cord injury: from inflammation to glial scar," Surgical Neurology International, vol. 2, article 112, 2011.

[33] L. Mao, H. Wang, L. Qiao, and X. Wang, "Disruption of Nrf2 enhances the upregulation of nuclear factor-kappaB activity, tumor necrosis factor- $\alpha$, and matrix metalloproteinase- 9 after spinal cord injury in mice," Mediators of Inflammation, vol. 2010, Article ID 238321, 10 pages, 2010.

[34] R. E. White, M. Rao, J. C. Gensel, D. M. McTigue, B. K. Kaspar, and L. B. Jakeman, "Transforming growth factor $\alpha$ transforms astrocytes to a growth-supportive phenotype after spinal cord injury," Journal of Neuroscience, vol. 31, no. 42, pp. 15173-15187, 2011.

[35] G. Chen, S. Zhang, J. Shi, J. Ai, M. Qi, and C. Hang, "Simvastatin reduces secondary brain injury caused by cortical contusion in rats: possible involvement of TLR4/NF- $\kappa \mathrm{B}$ pathway," Experimental Neurology, vol. 216, no. 2, pp. 398-406, 2009.

[36] E. D. Hall, R. A. Vaishnav, and A. G. Mustafa, "Antioxidant therapies for traumatic brain injury," Neurotherapeutics, vol. 7, no. 1, pp. 51-61, 2010.

[37] C. A. O'Connor, I. Cernak, and R. Vink, "Both estrogen and progesterone attenuate edema formation following diffuse traumatic brain injury in rats," Brain Research, vol. 1062, no. 1-2, pp. 171-174, 2005.

[38] N. Tas, B. Bakar, M. O. Kasimcan et al., "Evaluation of protective effects of the alpha lipoic acid after spinal cord injury: an animal study," Injury, vol. 41, no. 10, pp. 1068-1074, 2010.

[39] R. J. Reiter, D.-X. Tan, M. P. Terron, L. J. Flores, and Z. Czarnocki, "Melatonin and its metabolites: new findings regarding their production and their radical scavenging actions," Acta Biochimica Polonica, vol. 54, no. 1, pp. 1-9, 2007.

[40] J. B. Zawilska, D. J. Skene, and J. Arendt, "Physiology and pharmacology of melatonin in relation to biological rhythms," Pharmacological Reports, vol. 61, no. 3, pp. 383-410, 2009.

[41] D.-X. Tan, L. C. Manchester, E. Sanchez-Barcelo, M. D. Mediavilla, and R. J. Reiter, "Significance of high levels of endogenous melatonin in mammalian cerebrospinal fluid and in the central nervous system," Current Neuropharmacology, vol. 8, no. 3, pp. 162-167, 2010.

[42] Y. Zhao, D.-X. Tan, Q. Lei et al., "Melatonin and its potential biological functions in the fruits of sweet cherry," Journal of Pineal Research, vol. 55, no. 1, pp. 79-88, 2013.

[43] E. Esposito and S. Cuzzocrea, "Antiinflammatory activity of melatonin in central nervous system," Current Neuropharmacology, vol. 8, no. 3, pp. 228-242, 2010.

[44] A. Galano, D. X. Tan, and R. J. Reiter, "Melatonin as a natural ally against oxidative stress: a physicochemical examination," Journal of Pineal Research, vol. 51, no. 1, pp. 1-16, 2011. 
[45] G. M. Brown, D. P. Cardinali, and S. R. Pandi-Perumal, "Melatonin and mental illness," in Sleep and Mental Illness, S. R. Pandi-Perumal and M. Kramer, Eds., pp. 119-129, Cambridge University Press, Cambridge, UK, 2010.

[46] M. F. McCarty, "Minimizing the cancer-promotional activity of cox-2 as a central strategy in cancer prevention," Medical Hypotheses, vol. 78, no. 1, pp. 45-57, 2012.

[47] R. Santoro, M. Marani, G. Blandino, P. Muti, and S. Strano, "Melatonin triggers $\mathrm{p} 53^{\mathrm{Ser}}$ phosphorylation and prevents DNA damage accumulation," Oncogene, vol. 31, no. 24, pp. 2931-2942, 2012.

[48] A. Mehta and G. Kaur, "Potential role of melatonin in prevention and treatment of oral carcinoma," Indian Journal of Dentistry, vol. 5, Supplement, pp. 56-61, 2014.

[49] B. V. Jardim, L. C. Ferreira, T. F. Borin et al., "Evaluation of the anti-angiogenic action of melatonin in breast cancer," $B M C$ Proceedings, vol. 7, supplement 2, p. P11, 2013.

[50] D. P. Cardinali, V. Srinivasan, A. Brzezinski, and G. M. Brown, "Melatonin and its analogs in insomnia and depression," Journal of Pineal Research, vol. 52, no. 4, pp. 365-375, 2012.

[51] Y.-H. Wu, J. Ursinus, J.-N. Zhou et al., "Alterations of melatonin receptors MT1 and MT2 in the hypothalamic suprachiasmatic nucleus during depression," Journal of Affective Disorders, vol. 148, no. 2-3, pp. 357-367, 2013.

[52] S. R. Pandi-Perumal, A. S. Bahammam, G. M. Brown et al., "Melatonin antioxidative defense: therapeutical implications for aging and neurodegenerative processes," Neurotoxicity Research, vol. 23, no. 3, pp. 267-300, 2013.

[53] I. Kostoglou-Athanassiou, "Therapeutic applications of melatonin," Therapeutic Advances in Endocrinology and Metabolism, vol. 4, no. 1, pp. 13-24, 2013.

[54] K. Shinozuka, M. Staples, and C. V. Borlongan, "Melatoninbased therapeutics for neuroprotection in stroke," International Journal of Molecular Sciences, vol. 14, no. 5, pp. 8924-8947, 2013.

[55] P. Sarti, M. C. Magnifico, F. Altieri, D. Mastronicola, and M. Arese, "New evidence for cross talk between melatonin and mitochondria mediated by a circadian-compatible interaction with nitric oxide," International Journal of Molecular Sciences, vol. 14, no. 6, pp. 11259-11276, 2013.

[56] S. V. Kabadi and T. J. Maher, "Posttreatment with uridine and melatonin following traumatic brain injury reduces edema in various brain regions in rats," Annals of the New York Academy of Sciences, vol. 1199, pp. 105-113, 2010.

[57] X. Wang, "The antiapoptotic activity of melatonin in neurodegenerative diseases," CNS Neuroscience \& Therapeutics, vol. 15, no. 4, pp. 345-357, 2009.

[58] C.-M. Chern, J.-F. Liao, Y.-H. Wang, and Y.-C. Shen, "Melatonin ameliorates neural function by promoting endogenous neurogenesis through the MT2 melatonin receptor in ischemic-stroke mice," Free Radical Biology \& Medicine, vol. 52, no. 9, pp. 16341647, 2012.

[59] F. Dehghan, M. Khaksari Hadad, G. Asadikram, H. Najafipour, and N. Shahrokhi, "Effect of melatonin on intracranial pressure and brain edema following traumatic brain injury: role of oxidative stresses," Archives of Medical Research, vol. 44, no. 4, pp. 251-258, 2013.

[60] N. K. Singhal, G. Srivastava, D. K. Patel, S. K. Jain, and M. P. Singh, "Melatonin or silymarin reduces maneb- and paraquatinduced Parkinsons disease phenotype in the mouse," Journal of Pineal Research, vol. 50, no. 2, pp. 97-109, 2011.
[61] R. Hardeland, D.-X. Tan, and R. J. Reiter, "Kynuramines, metabolites of melatonin and other indoles: the resurrection of an almost forgotten class of biogenic amines," Journal of Pineal Research, vol. 47, no. 2, pp. 109-126, 2009.

[62] M. A. Ahmed, H. I. Ahmed, and E. M. El-Morsy, "Melatonin protects against diazinon-induced neurobehavioral changes in rats," Neurochemical Research, vol. 38, no. 10, pp. 2227-2236, 2013.

[63] E. A. Wilhelm, C. R. Jesse, C. F. Bortolatto, and C. W. Nogueira, "Correlations between behavioural and oxidative parameters in a rat quinolinic acid model of Huntington's disease: protective effect of melatonin," European Journal of Pharmacology, vol. 701, no. 1-3, pp. 65-72, 2013.

[64] A. Cruz, I. Túnez, R. Martínez et al., "Melatonin prevents brain oxidative stress induced by obstructive jaundice in rats," Journal of Neuroscience Research, vol. 85, no. 16, pp. 3652-3656, 2007.

[65] J. J. Breunig, M.-V. Guillot-Sestier, and T. Town, "Brain injury, neuroinflammation and Alzheimer's disease," Frontiers in Aging Neuroscience, vol. 5, article 26, 2013.

[66] V. R. Feeser and R. M. Loria, "Modulation of traumatic brain injury using progesterone and the role of glial cells on its neuroprotective actions," Journal of Neuroimmunology, vol. 237, no. 1-2, pp. 4-12, 2011.

[67] E. Kenne, A. Erlandsson, L. Lindbom, L. Hillered, and F. Clausen, "Neutrophil depletion reduces edema formation and tissue loss following traumatic brain injury in mice," Journal of Neuroinflammation, vol. 9, article 17, 2012.

[68] O. Sanz, L. Acarin, B. González, and B. Castellano, "NF- $\kappa$ B and $\mathrm{I} \kappa \mathrm{b} \alpha$ expression following traumatic brain injury to the immature rat brain," Journal of Neuroscience Research, vol. 67, no. 6, pp. 772-780, 2002.

[69] S. M. Beni, R. Kohen, R. J. Reiter, D.-X. Tan, and E. Shohami, "Melatonin-induced neuroprotection after closed head injury is associated with increased brain antioxidants and attenuated late-phase activation of NF- $\kappa \mathrm{B}$ and AP-1," The FASEB Journal, vol. 18, no. 1, pp. 149-151, 2004.

[70] R. D. Readnower, M. Chavko, S. Adeeb et al., "Increase in blood-brain barrier permeability, oxidative stress, and activated microglia in a rat model of blast-induced traumatic brain injury," Journal of Neuroscience Research, vol. 88, no. 16, pp. 3530-3539, 2010

[71] D. Shlosberg, M. Benifla, D. Kaufer, and A. Friedman, "Bloodbrain barrier breakdown as a therapeutic target in traumatic brain injury," Nature Reviews Neurology, vol. 6, no. 7, pp. 393403, 2010.

[72] O. Tomkins, A. Feintuch, M. Benifla, A. Cohen, A. Friedman, and I. Shelef, "Blood-brain barrier breakdown following traumatic brain injury: a possible role in posttraumatic epilepsy," Cardiovascular Psychiatry and Neurology, vol. 2011, Article ID 765923, 11 pages, 2011.

[73] M.-F. Ritz and O. N. Hausmann, "Effect of $17 \beta$-estradiol on functional outcome, release of cytokines, astrocyte reactivity and inflammatory spreading after spinal cord injury in male rats," Brain Research, vol. 1203, pp. 177-188, 2008.

[74] D. J. Donnelly and P. G. Popovich, "Inflammation and its role in neuroprotection, axonal regeneration and functional recovery after spinal cord injury," Experimental Neurology, vol. 209, no. 2, pp. 378-388, 2008.

[75] M. Szczepanik, "Melatonin and its influence on immune system," Journal of Physiology and Pharmacology, vol. 58, no. 6, pp. 115-124, 2007. 
[76] A. Schiaveto-de-Souza, C. A. da-Silva, H. L. A. Defino, and E. A. del Bel, "Effect of melatonin on the functional recovery from experimental traumatic compression of the spinal cord," Brazilian Journal of Medical and Biological Research, vol. 46, no. 4, pp. 348-358, 2013.

[77] Q. Fang, G. Chen, W. Zhu, W. Dong, and Z. Wang, "Influence of melatonin on cerebrovascular proinflammatory mediators expression and oxidative stress following subarachnoid hemorrhage in rabbits," Mediators of Inflammation, vol. 2009, Article ID 426346, 6 pages, 2009.

[78] T. Genovese, E. Mazzon, C. Muià, P. Bramanti, A. de Sarro, and S. Cuzzocrea, "Attenuation in the evolution of experimental spinal cord trauma by treatment with melatonin," Journal of Pineal Research, vol. 38, no. 3, pp. 198-208, 2005.

[79] D. A. Drechsel, A. G. Estévez, L. Barbeito, and J. S. Beckman, "Nitric oxide-mediated oxidative damage and the progressive demise of motor neurons in ALS," Neurotoxicity Research, vol. 22, no. 4, pp. 251-264, 2012.

[80] V. Calabrese, C. Cornelius, E. Rizzarelli, J. B. Owen, A. T. Dinkova-Kostova, and D. A. Butterfield, "Nitric oxide in cell survival: a Janus molecule," Antioxidants \& Redox Signaling, vol. 11, no. 11, pp. 2717-2739, 2009.

[81] K. Kuboyama, M. Tsuda, M. Tsutsui et al., "Reduced spinal microglial activation and neuropathic pain after nerve injury in mice lacking all three nitric oxide synthases," Molecular Pain, vol. 7, article 50, 2011.

[82] P. Tripathi, "Nitric oxide and immune response," Indian Journal of Biochemistry and Biophysics, vol. 44, no. 5, pp. 310-319, 2007.

[83] R.-R. Ji, R. W. Gereau IV, M. Malcangio, and G. R. Strichartz, "MAP kinase and pain," Brain Research Reviews, vol. 60, no. 1, pp. 135-148, 2009.

[84] S. W. Scheff, M. A. Ansari, and K. N. Roberts, "Neuroprotective effect of Pycnogenol following traumatic brain injury," Experimental Neurology, vol. 239, no. 1, pp. 183-191, 2013.

[85] T. Genovese, E. Esposito, E. Mazzon et al., "Evidence for the role of mitogen-activated protein kinase signaling pathways in the development of spinal cord injury," Journal of Pharmacology and Experimental Therapeutics, vol. 325, no. 1, pp. 100-114, 2008.

[86] E. Esposito, T. Genovese, R. Caminiti, P. Bramanti, R. Meli, and S. Cuzzocrea, "Melatonin reduces stress-activated/mitogenactivated protein kinases in spinal cord injury," Journal of Pineal Research, vol. 46, no. 1, pp. 79-86, 2009.

[87] A. F. Cristante, T. E. P. de Barros Filho, R. M. Marcon, O. B. Letaif, and I. D. da Rocha, "Therapeutic approaches for spinal cord injury," Clinics, vol. 67, no. 10, pp. 1219-1224, 2012.

[88] T. Lam, Z. Chen, M. M. Sayed-Ahmed, A. Krassioukov, and A. A. Al-Yahya, "Potential role of oxidative stress on the prescription of rehabilitation interventions in spinal cord injury," Spinal Cord, vol. 51, no. 9, pp. 656-662, 2013.

[89] R. J. Reiter, L. C. Manchester, and D.-X. Tan, "Neurotoxins: free radical mechanisms and melatonin protection," Current Neuropharmacology, vol. 8, no. 3, pp. 194-210, 2010.

[90] M. Erşahin, Z. Özdemir, D. Özsavcı et al., "Melatonin treatment protects against spinal cord injury induced functional and biochemical changes in rat urinary bladder," Journal of Pineal Research, vol. 52, no. 3, pp. 340-348, 2012.

[91] M. C. Albertini, F. Radogna, A. Accorsi et al., "Intracellular prooxidant activity of melatonin deprives U937 cells of reduced glutathione without affecting glutathione peroxidase activity," Annals of the New York Academy of Sciences, vol. 1091, pp. 1016, 2006.
[92] M. Büyükavci, Ö. Özdemir, S. Buck, M. Stout, Y. Ravindranath, and S. Savaşan, "Melatonin cytotoxicity in human leukemia cells: relation with its pro-oxidant effect," Fundamental and Clinical Pharmacology, vol. 20, no. 1, pp. 73-79, 2006.

[93] S. Eskiocak, F. Tutunculer, U. N. Basaran, A. Taskiran, and E. Cakir, "The effect of melatonin on protein oxidation and nitric oxide in the brain tissue of hypoxic neonatal rats," Brain and Development, vol. 29, no. 1, pp. 19-24, 2007.

[94] D. Gonzalez, J. Espino, I. Bejarano, A. B. Rodriguez, and J. A. Pariente, " $\mathrm{H}_{2} \mathrm{O}_{2}$-induced caspase activation is dependent of calcium signal in HL-60 cells," Current Signal Transduction Therapy, vol. 25, pp. 181-186, 2010.

[95] I. Bejarano, J. Espino, D. González-Flores et al., "Role of calcium signals on hydrogen peroxide-induced apoptosis in human myeloid HL-60 cells," International Journal of Biomedical Science, vol. 5, no. 3, pp. 246-256, 2009.

[96] J. I. Chuang, T. Y. Chang, and H. S. Liu, "Glutathione depletioninduced apoptosis of Ha-ras-transformed NIH3T3 cells can be prevented by melatonin," Oncogene, vol. 22, no. 9, pp. 1349-1357, 2003.

[97] F. Luchetti, B. Canonico, R. Curci et al., "Melatonin prevents apoptosis induced by UV-B treatment in U937 cell line," Journal of Pineal Research, vol. 40, no. 2, pp. 158-167, 2006.

[98] F. C. Muñoz-Casares, F. J. Padillo, J. Briceño et al., "Melatonin reduces apoptosis and necrosis induced by ischemia/reperfusion injury of the pancreas," Journal of Pineal Research, vol. 40, no. 3, pp. 195-203, 2006.

[99] I. Bejarano, P. C. Redondo, J. Espino et al., "Melatonin induces mitochondrial-mediated apoptosis in human myeloid HL-60 cells," Journal of Pineal Research, vol. 46, no. 4, pp. 392-400, 2009.

[100] S. Rubio, F. Estévez, J. Cabrera, R. J. Reiter, J. Loro, and J. Quintana, "Inhibition of proliferation and induction of apoptosis by melatonin in human myeloid HL-60 cells," Journal of Pineal Research, vol. 42, no. 2, pp. 131-138, 2007.

[101] I. Bejarano, J. Espino, C. Barriga, R. J. Reiter, J. A. Pariente, and A. B. Rodríguez, "Pro-oxidant effect of melatonin in tumour leucocytes: relation with its cytotoxic and pro-apoptotic effects," Basic and Clinical Pharmacology and Toxicology, vol. 108, no. 1, pp. 14-20, 2011.

[102] A. P. C. Batista, T. G. da Silva, Á. A. C. Teixeira et al., "Ultrastructural aspects of melatonin cytotoxicity on Caco-2 cells in vitro," Micron, vol. 59, pp. 17-23, 2014.

[103] A. Wolfler, H. C. Caluba, P. M. Abuja, G. Dohr, K. Schauenstein, and P. M. Liebmann, "Prooxidant activity of melatonin promotes fas-induced cell death in human leukemic Jurkat cells," FEBS Letters, vol. 502, no. 3, pp. 127-131, 2001.

[104] E.-J. Lee, M.-Y. Lee, H.-Y. Chen et al., "Melatonin attenuates gray and white matter damage in a mouse model of transient focal cerebral ischemia," Journal of Pineal Research, vol. 38, no. 1, pp. 42-52, 2005.

[105] P.-O. Koh, "Melatonin regulates the calcium-buffering proteins, parvalbumin and hippocalcin, in ischemic brain injury," Journal of Pineal Research, vol. 53, no. 4, pp. 358-365, 2012.

[106] P.-O. Koh, "Melatonin prevents down-regulation of astrocytic phosphoprotein PEA-15 in ischemic brain injury," Journal of Pineal Research, vol. 51, no. 4, pp. 381-386, 2011.

[107] M. Kerman, B. Cirak, M. F. Ozguner et al., "Does melatonin protect or treat brain damage from traumatic oxidative stress?" Experimental Brain Research, vol. 163, no. 3, pp. 406-410, 2005. 
[108] T. Al-Aama, C. Brymer, I. Gutmanis, S. M. WoolmoreGoodwin, J. Esbaugh, and M. Dasgupta, "Melatonin decreases delirium in elderly patients: a randomized, placebo-controlled trial," International Journal of Geriatric Psychiatry, vol. 26, no. 7, pp. 687-694, 2011.

[109] K. Asayama, H. Yamadera, T. Ito, H. Suzuki, Y. Kudo, and S. Endo, "Double blind study of melatonin effects on the sleep-wake rhythm, cognitive and non-cognitive functions in Alzheimer type dementia," Journal of Nippon Medical School, vol. 70, no. 4, pp. 334-341, 2003.

[110] M. A. Seifman, A. A. Adamides, P. N. Nguyen et al., "Endogenous melatonin increases in cerebrospinal fluid of patients after severe traumatic brain injury and correlates with oxidative stress and metabolic disarray," Journal of Cerebral Blood Flow and Metabolism, vol. 28, no. 4, pp. 684-696, 2008. 

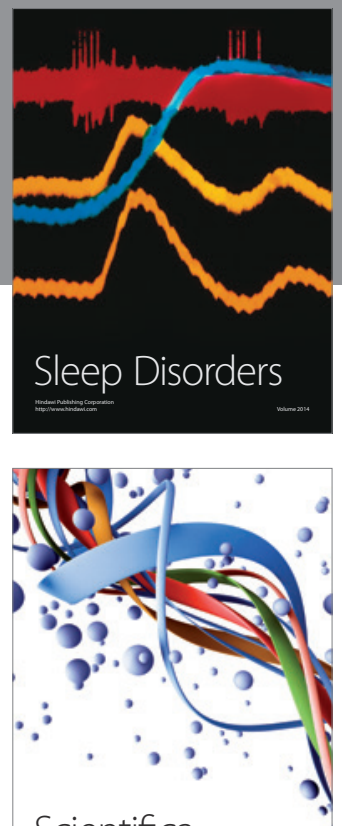

Scientifica
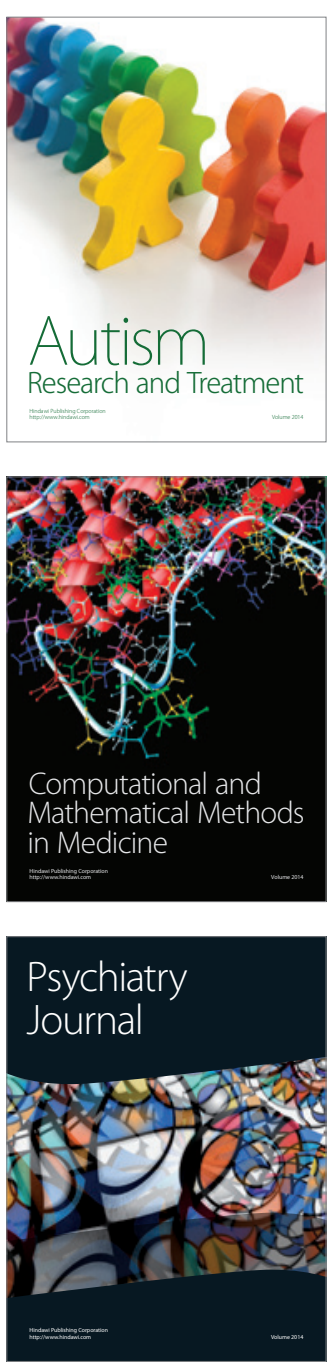
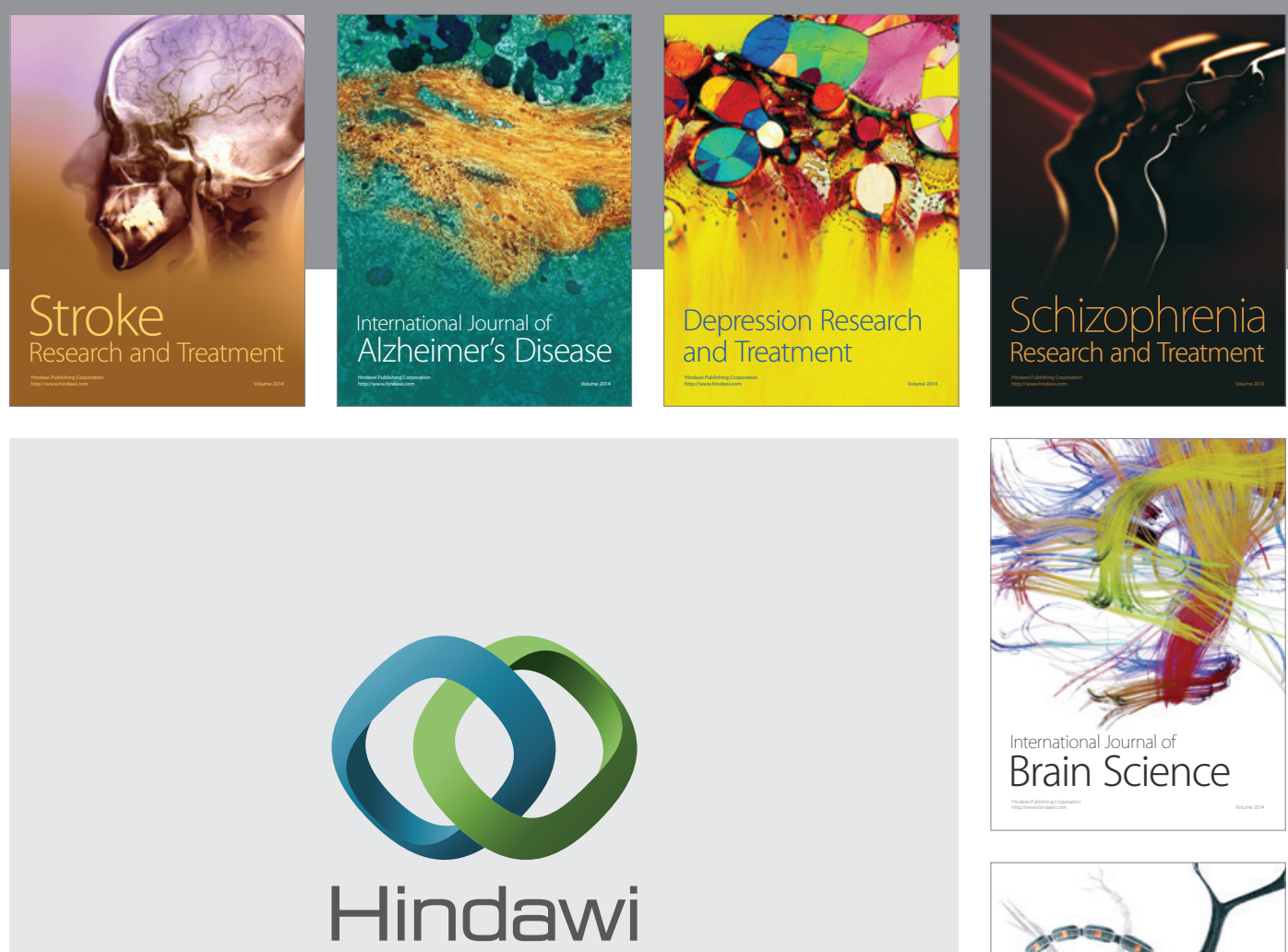

Submit your manuscripts at

http://www.hindawi.com
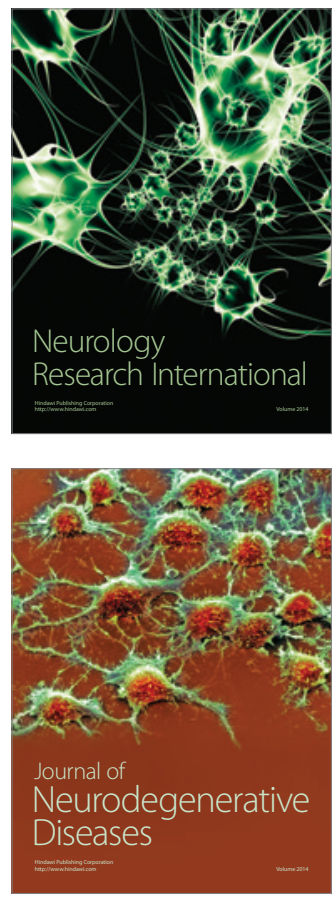

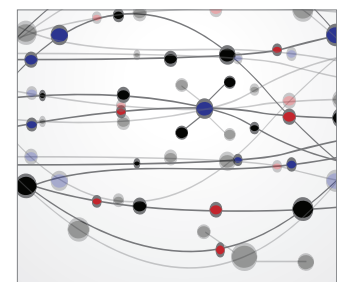

The Scientific World Journal
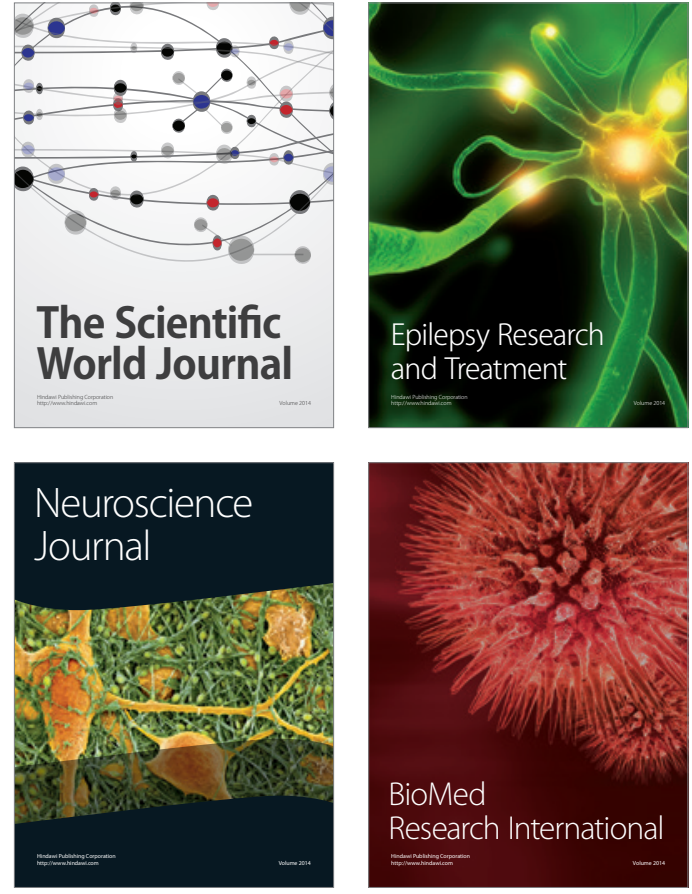

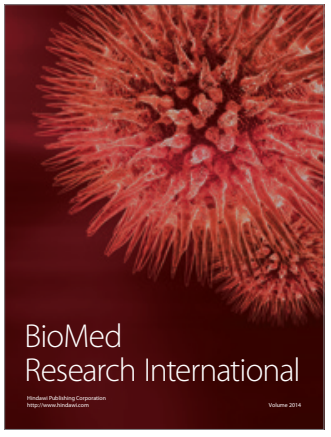

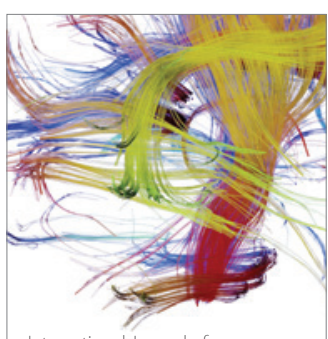

Brain Science

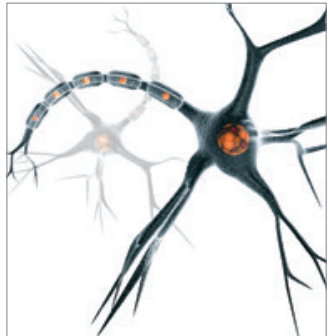

Neural Plasticity
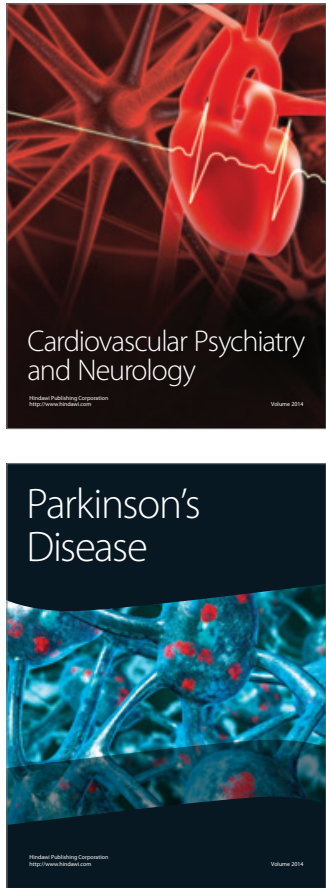